\title{
PREFERENSI KONSUMEN GULA PASIR TERHADAP PRODUK, HARGA, PROMOSI, DAN DISTRIBUSI
}

\author{
Amarullah Sofa ${ }^{a}$ \\ Badri Munir Sukocob \\ ${ }^{a}$ Sekolah Pascasarjana Universitas Airlangga ${ }^{b}$ Fakultas Ekonomi dan Bisnis Universitas Airlangga \\ Email: s.amarullah@yandex.com ${ }^{\text {a }}$ badri@feb.unair.ac.id ${ }^{\text {b }}$
}

ARTICLE HISTORY

Received:

1 Februari 2019

Revised

3 March 2019

Accepted:

19 March 2019

Online available:

14 Mei 2019

Keywords:

Sugar, B2B, Product, Price, Promotion, Distribution, and PTPN $\mathrm{XI}$

Kata Kunci: Gula, B2B, Produk, Harga, Promosi, Distribusi, dan PTPN XI

\section{ABSTRACT}

Introduction: Distribution system of PTPN XI depends on the tender of regulation that affects benefit for PTPN XI. Java Seven Samurai which act as bidders. This study is expected to provide important information on PTPN XI and stimulus-dependent regulation of Seven Samurai, in order to sell new sugar products directly to the consumer so that the resulting higher profits.

Methods: This research is a non-experimental study that performs data collection at a certain time for the sample group (cross-sectional). The research approach used in this study is a qualitative descriptive analysis approach to processing primary data obtained from the research sample. Results: The results of this study, new favorite sugar characteristics are: 1) Product: consumers prefer brands using Indonesian sugar, sugars crystals are white clearly color, and odorless; 2) Price: consumers like discounts and bonuses given to purchase a lot and adjust the size of the price change per pack; 3 ) Promotion: social media are easily found and preferred customer is Facebook; 4) Distribution: traditional marketing is a consumer preferred shop and agents while modern retail customers preferred is a minimarket.

Conclusion and suggestion: Sugar is distributed directly from PTPN XI preferably at minimarket and agents. While distribution is lacking indirectly (through an agent) is a traditional store. 


\section{ABSTRAK}

Sistem distribusi PTPN XI bergantung pada regulasi tender yang berdampak pada keuntungan bagi PTPN XI. Java Seven Samurai yang bertindak sebagai penawar. Penelitian ini diharapkan dapat memberikan informasi penting tentang PTPN XI dan regulasi yang bergantung pada stimulus dari Seven Samurai, agar dapat menjual produk gula baru langsung ke konsumen sehingga menghasilkan keuntungan yang lebih tinggi. Hasil penelitian, karakteristik gula favorit baru adalah: 1) Produk: konsumen lebih menyukai merek yang menggunakan gula Indonesia, gula kristal berwarna putih jelas, dan tidak berbau; 2) Harga: konsumen menyukai diskon dan bonus yang diberikan untuk membeli banyak dan menyesuaikan ukuran perubahan harga per bungkus; 3) Promosi: media sosial mudah ditemukan dan pelanggan yang disukai adalah Facebook; 4) Distribusi: pemasaran tradisional adalah toko dan agen yang disukai konsumen sedangkan yang disukai konsumen ritel modern adalah minimarket. Gula didistribusikan langsung dari PTPN XI lebih disukai di minimarket dan agen. Sedangkan distribusinya yang kurang secara tidak langsung (melalui agen) adalah toko tradisional.

\section{INTRODUCTION}

Gula pasir adalah salah satu komoditas pertanian yang telah ditetapkan oleh pemerintah Indonesia sebagai komoditas khusus (special products) dan bahan pemanis utama. Secara nasional kebutuhan gula untuk konsumsi rumah tangga saja mencapai sekitar 2,97 juta ton Gula Kristal Putih (GKP) per tahun, atau sekitar 250 ton per bulan (Suhasnan, 2012). PT Perkebunan Nusantara XI (Persero) atau PTPN XI adalah Badan Usaha Milik Negara (BUMN) agribisnis perkebunan dengan core business gula (Hafid, 2010). PTPN XI (Persero) yang membawahi 16 Pabrik Gula (PG) di Jawa Timur telah merevitalisasi dua PG dengan potensi giling dan produksi besar. Kedua PG yang direvitalisasi yakni PG Djatiroto Kabupaten Lumajang dan PG Semboro Kabupaten Jember (Rahayu, 2011).

Pabrik Gula Djatiroto merupakan salah satu dari 16 pabrik yang dimiliki PTPN XI. Pada tahun 2013, PG Djatiroto menargetkan untuk produksi gula sekitar 450 ribu ton (Pemkab Lumajang, 2014). PG Semboro berada di kecataman Semboro, Kabupaten Jember (Hafid, 2010). Gula premium produksi PG Semboro merupakan produk unggulan yang tidak hanya kualitas dan mutunya mendekati gula rafinasi, tetapi dari sudut pandang kesehatan relatif bebas dari residu dan zat adiktif (Sandro, 2013; PTPN XI, 2009). Tetapi, PG Djatiroto dan Semboro belum mempunyai varian produk gula baru yang sesuai dengan keinginan keberagaman konsumen (Surabaya Pagi, 2013).

Bagi perusahaan yang bergerak di bidang produksi, PT. Perkebunan Nuasantara XI (Persero) yang bergerak dibidang produksi gula, tidak akan lepas dari mencari keuntungan optimal. Sistem distribusi gula pasir di PTPN XI begantung pada regulasi 
sistem tender yang berdampak kurang maksimalnya keuntungan bagi pihak PTPN XI. Ketua Asosiasi Pengusaha Pendistribusian Gula Sumatera Utara (AP2SU), Anton Panggabean menyatakan bahwa harga gula ditentukan oleh tujuh perusahaan gula yang sering disebut Tujuh Samurai di daerah Jawa yang bertindak sebagai pelaku tender. Ketujuh perusahaan raksasa ini yang telah melakukan monopoli pasar gula (Harian Sumut Pos, 2009).

Sekelompok pedagang gula disebut samurai yang mengontrol pasar dan harga eceran gula sehingga membuat harga di Indonesia termasuk tertinggi di Asia. Samurai mempunyai sistem untuk membeli gula dengan mengorbankan pedagang lain pada kondisi tertentu. Samurai juga mengelola sebagian besar jaringan distribusi dan ritel, memberikan mereka penguasaan hampir total terhadap pasar dan harga eceran gula. Sebagian besar gula dilelang di tempat-tempat yang dikelola para penggilingan dalam jumlah sedikit. Hal itu menguntungkan bagi para samurai, namun tidak untuk perusahaan-perusahaan besar yang lebih suka membeli sejumlah besar komoditas karena lebih ekonomis dan agar biaya transaksi turun (VOA, 2014).

Tujuh Samurai mulai mendominasi pasar gula pasir setelah krisis keuangan Asia pada 1998, saat Presiden Soeharto lengser dan International Monetary Fund memaksakan berbagai reformasi pertanian dengan imbalan pinjaman. Samurai juga mendapatkan keuntungan lain melalui perjanjian yang sudah ada lebih dari satu dekade, dengan para samurai meminjamkan uang kepada petani untuk menanam kembali. Beberapa petani membayar bunga atas pinjaman tersebut sementara yang lainnya berbagi keuntungan. Kedua skema tersebut para samurai mendapatkan hak istimewa dalam lelang. Samurai berhak untuk membeli hingga 50 persen dari tawaran apa pun yang menang, dengan harga yang sama pada ladang yang mereka biayai. Samurai telah memperketat kontrol retail dan saluran pengiriman melalui jasa transportasi, pergudangan, dan agen mereka sendiri selama bertahun-tahun. Seorang pedagang (nonsamurai) akan kesulitan untuk mendapatkan tempat lelang untuk pasar (Taylor dan Yayat, 2013).

Dari beberapa fenomena tentang Tujuh Samurai tersebut, memberikan sebuah rekomendasi bahwa PTPN XI hendaknya tidak menggunakan regulasi tender via Tujuh Samurai. Hal ini bertujuan agar PTPN XI dapat mengurangi ketergantungan pada Tujuh Samurai. Selain itu dengan terlepasnya PTPN XI dari ikatan regulasi Tujuh Samurai berpotensi mempersingkat rantai distribusi produk dari produsen langsung pada konsumen. Sehingga harapannya, dapat memberikan peningkatan keuntungan bagi PTPN XI serta dapat mendongkrak efisiensi produksi secara langsung.

Solusi yang ditawarkan untuk menghilangkan ketergantungan pada tujuh samurai pada penelitian ini adalah melalui cara memproduksi gula yang sesuai dengan keinginan konsumen. Untuk mengetahui keinginan konsumen itu peneliti melakukan survei kepada 
agen dan toko (tradisional dan modern). Sasaran tersebut dipilih karena mereka (agen dan toko) yang lebih mengetahui keinginan konsumen tentang gula. Upaya untuk mencapai strategi pemasaran yang tepat dan terbaik untuk diterapkan, perusahaan dapat melihat dari faktor bauran pemasaran (Marketing Mix). Istilah bauran pemasaran digunakan untuk menggambarkan set variabel pemasaran yang dipakai oleh organisasi untuk menghasilkan pertukaran dengan konsumen (Fayshal, 2013; Goodwin, 1994).

Konsep pemasaran yang digunakan sebagai dasar adalah melalui konsep kerja sama Business to Business (B2B) yang ditinjau dari empat variabel (4P) yaitu bauran product (produk), price (harga), promotion (promosi), dan place (distribusi). Manfaat dan keunggulan layanan $B 2 B$ antara lain (Hernawan, 2012; Roberts et al, 2005): (1) lebih efektif di setiap tahap penjualan, dapat secara rinci menentukan prioritas, strategi, dan bisnis pelanggan; (2) tidak perlu melewati proses negosiasi harga yang panjang, karena dilakukan pada awal kesepakatan kerja sama; (3) mengurangi biaya perusahaan untuk administrasi, surat menyurat transaksi, ataupun untuk riset harga pasar. Dengan demikian, faktor yang ada dalam bauran pemasaran (marketing mix) merupakan variabel-variabel yang diharapkan mampu menciptakan kepuasan konsumen, atau dengan kata lain variabel-variabel tersebut akan mempengaruhi kepuasan konsumen dalam membeli suatu produk. Kepuasan pelanggan akan berimbas kepada loyalitas pelanggan, sehingga usaha yang dibangun akan terus bertahan dan berkembang (Rachmawati, 2011). Hal ini dikarenakan PTPN XI bergantung pada regulasi Tujuh Samurai, jika dapat menjual produk gula langsung ke konsumen keuntungan akan lebih tinggi.

Upaya memenuhi keinginan konsumen terhadap gula pasir, industri memerlukan atribut-atribut yang dianggap penting untuk konsumennya. Penelitian ini berupaya menghasilkan konsep produk baru yang paling diinginkan sesuai preferensi responden. Konsep produk gula pasir yang diharapkan terbentuk adalah diuraikan berdasarkan kombinasi elemen produk, harga, promosi, dan distribusi dengan menggunakan Marketing Mix. Semua kondisi ini menarik untuk dikaji, yang menjadi pertimbangan bagi konsumen dalam memilih gula pasir untuk di konsumsi dan faktor yang paling penting sebagai pertimbangan konsumen dalam memutuskan membeli dan mengkonsumsi gula pasir.

\section{LITERATURE REVIEW}

\section{Business-to-Business Marketing (B2B)}

Business-to-Business (B2B) menggambarkan transaksi perdagangan antara perusahaan, seperti antara produsen dan grosir, atau antara grosir dan pengecer. Pemasaran $B 2 B$ diincar banyak perusahaan, karena volume dan nilai penjulalan jauh 
lebih besar dibanding menjual ke konsumen perorangan dan rantai pemasaran lebih pendek (Roberts et al, 2005). Pemasar menerapkan Business to Business, berorientasi pada pemenuhan kebutuhan pembeli, tidak pada penjualan produk. Jadi, penjual produk 4 bukan lagi merupakan target akhir pemasaran Business to Business, melainkan bagaimana memenuhi kebutuhan pembeli sehingga kerjasama itu dapat berlangsung dengan jangka panjang.

\section{Marketing Mix}

Upaya untuk mencapai strategi pemasaran yang tepat dan terbaik untuk diterapkan, perusahaan dapat melihat dari faktor bauran pemasaran (Marketing Mix). Istilah bauran pemasaran digunakan untuk menggambarkan set variabel pemasaran yang dipakai oleh organisasi untuk menghasilkan pertukaran dengan konsumen (Fayshal, 2013; Goodwin, 1994). Faktor-faktor yang membentuk bauran pemasaran umumnya dikategorikan menjadi empat variabel (4P) yaitu product (produk), price (harga), promotion (promosi), dan place (distribusi). Menurut Kotler (1997) diuraikan beberapa konsep yakni: (1) product (produk) merupakan kombinasi barang dan jasa yang ditawarkan; (2) price (harga) adalah jumlah uang yang harus dibayakan pelanggan untuk memperoleh produk; (3) place (tempat) meliputi kegiatan perusahaan yang membuat produk tersedia bagi pelanggan sasaran; (4) promotion (promosi) berarti aktivitas yang menyampaikan manfaat produk dan membujuk pelanggan membelinya.

\section{RESEARCH METHODS}

Penelitian ini merupakan penelitian non-eksperimen yang melakukan pengambilan data pada satu waktu tertentu untuk kelompok sampel (cross-sectional). Pendekatan penelitian yang digunakan dalam penelitian ini adalah pendekatan analisis deskriptif kualitatif untuk mengolah data primer yang diperoleh dari sampel penelitian. Berdasarkan tujuan penelitian yang telah ditetapkan peneliti, maka jenis penelitian yang digunakan adalah penelitian eksploratif (exploratory research).

Berdasarkan data Badan Pusat Statistik Kabupaten Lumajang dan Kabupaten Jember banyaknya toko tradisional lebih besar dibandingkan dengan minimarket (toko modern), serta yang paling sedikit jumlahnya adalah agen (BPS Jember, 2012; BPS Lumajang, 2012). Agar sampel proporsional maka teknik pembagian sampel menggunakan stratified purposive sampling. Peneliti memberikan toko yang besar dengan lebih banyak sampel penjual gula kesempatan yang lebih besar untuk diseleksi sebagai sampel. Dasar dari pengaturan itu adalah proporsi dari semua penjual gula dalam populasi yang akan diambil. 
Tabel 1

Jumlah Sampel di Kabupaten Lumajang dan Jember

\begin{tabular}{lccccccc}
\hline Kabupaten & Jumlah & \multicolumn{3}{c}{ Proporsi Sampel (\%) } & \multicolumn{3}{c}{ Jumlah Sampel (Jiwa) } \\
Sampel & Agen & Toko & Minimarket & Agen & Toko & minimarket \\
\hline Lumajang & 50 & 10 & 60 & 30 & 5 & 30 & 15 \\
Jember & 50 & 10 & 60 & 30 & 5 & 30 & 15 \\
Jumlah & 100 & & & & $\mathbf{1 0}$ & $\mathbf{6 0}$ & $\mathbf{3 0}$ \\
\hline
\end{tabular}

\section{RESULT AND ANALYSIS}

Jumlah Pelanggan Produk Gula di Toko, Minimarket, dan Agen

Tabel 2

Data Pelanggan di Kabupaten Lumajang

\begin{tabular}{|c|c|c|c|c|c|c|c|c|c|c|}
\hline \multirow{4}{*}{ Sasaran } & \multicolumn{10}{|c|}{ Jumlah Pelanggan } \\
\hline & \multirow{2}{*}{\multicolumn{2}{|c|}{$\begin{array}{c}<10 \\
\text { orang }\end{array}$}} & \multirow{2}{*}{\multicolumn{2}{|c|}{$\begin{array}{l}10-30 \\
\text { orang }\end{array}$}} & \multirow{2}{*}{\multicolumn{2}{|c|}{$\frac{31-70}{\text { orang }}$}} & \multicolumn{2}{|c|}{$71-100$} & \multirow{2}{*}{\multicolumn{2}{|c|}{ > 100 Orang }} \\
\hline & & & & & & & & orang & & \\
\hline & $\mathrm{F}$ & $\%$ & $f$ & $\%$ & $f$ & $\%$ & $f$ & $\%$ & $\mathrm{~F}$ & $\%$ \\
\hline Toko & 3 & 10,00 & 12 & 40,00 & 6 & 20,00 & 8 & 26,67 & 1 & 3,33 \\
\hline Minimarket & 0 & 0,00 & 0 & 0,00 & 6 & 40,00 & 7 & 46,67 & 2 & 13,33 \\
\hline Agen & 0 & 0,00 & 0 & 0,00 & 0 & 0,00 & 1 & 20,00 & 4 & 80,00 \\
\hline
\end{tabular}

Tabel 3

Data Pelanggan di Kabupaten Jember

\begin{tabular}{|c|c|c|c|c|c|c|c|c|c|c|}
\hline \multirow{4}{*}{ Sasaran } & \multicolumn{10}{|c|}{ Jumlah Pelanggan } \\
\hline & \multirow{2}{*}{\multicolumn{2}{|c|}{$\begin{array}{c}<10 \\
\text { orang }\end{array}$}} & \multirow{2}{*}{\multicolumn{2}{|c|}{$\begin{array}{l}10-30 \\
\text { orang }\end{array}$}} & \multirow{2}{*}{\multicolumn{2}{|c|}{$\begin{array}{l}31-70 \\
\text { orang }\end{array}$}} & \multicolumn{2}{|c|}{$71-100$} & \multirow{2}{*}{\multicolumn{2}{|c|}{$>100$ Orang }} \\
\hline & & & & & & & & orang & & \\
\hline & $\mathrm{F}$ & $\%$ & $\mathrm{f}$ & $\%$ & $f$ & $\%$ & $f$ & $\%$ & $\mathrm{~F}$ & $\%$ \\
\hline Toko & 4 & 13,33 & 16 & 53,33 & 7 & 23,33 & 3 & 10,00 & 0 & 0,00 \\
\hline Minimarket & 0 & 0,00 & 0 & 0,00 & 9 & 60,00 & 6 & 40,00 & 0 & 0,00 \\
\hline Agen & 0 & 0,00 & 0 & 0,00 & 0 & 0,00 & 2 & 40,00 & 3 & 60,00 \\
\hline
\end{tabular}

Persepsi Pelanggan Mengenai Produk Gula Perspektif Penjual Gula (Toko, Minimarket, dan Agen)

Penjual produk gula baik dari toko $(56,67 \%)$, minimarket $(80,00 \%)$, dan agen $(100,00 \%)$ di kebupaten Lumajang (letak PG Djatiroto) telah mempunyai pengalaman menjual produk gula lebih dari 12 bulan (> 1 tahun). Sehingga para penjual tersebut mengetahui preferensi konsumen akhir produk gula pasir. Berdasarkan keterangan rosponden menyatakan bahwa para konsumen membeli hampir setiap hari. Hal ini 
diasumsikan berdasarkan data yang menyatakan bahwa responden setiap hari melayani konsumen yang membeli gula pasir. Terdapat perbedaan kapasitas penjualan produk gula pasir pada tiap jenis retail. Berat gula yang dibeli konsumen di agen lebih besar daripada di minimarket dalam sekali pembelian. Pembelian gula di minimarket $(1 \mathrm{~kg})$ lebih besar daripada di toko tradisional ( $1 / 2 \mathrm{~kg})$ dalam sekali beli.

Berkenaan tentang perlunya penjualan produk gula bermerek atau tidak, data menunjukkan untuk retail toko tradisional $(40,00 \%)$ dan agen $(100,00 \%)$, produk gula bermerek tidak diperlukan. Karena konsumen beli atas landasan kebutuhan tidak sekedar keinginan seperti halnya pembelian yang dilakukan di minimarket dengan dominasi produk yang sering dibeli yakni merek Gulaku $(60,00 \%)$. Berdasarkan data tingkat kepuasan konsumen, konsumen gula berpendapat bahwa gula yang selama ini mereka gunakan sangat bersih (toko: 66,67\%; minimarket: 93,33\%; agen: 60,00\%) sehingga PTPN XI hendaknya mempertahankan predikat kualitas produksi tersebut. Tetapi untuk kebutuhan pelanggan tiap retail berbeda. Pelanggan yang membeli di toko lebih suka gula yang lembut $(36,67 \%)$. Sedangkan di minimarket lebih berkenan dengan yang kasar (46,67\%). Begitu pula di agen berkeinginan gula sangat kasar (60,00\%).

Aroma gula pasir pada konsumen semua retail memiliki kesamaan selera, konsumen lebih suka produk gula yang netral (tidak berbau) (toko: 83,33\%; minimarket: 66,67\%; agen: $100,00 \%)$ hal ini dikarenakan produk gula yang aromanya netral sudah dapat dipastikan gula terjaga kebersihannya. Persepsi konsumen terhadap kemasan gula yang dijual di toko tidak kuat (66,67\%). Sedangkan di minimarket cukup kuat $(66,67 \%)$, dan predikat sangat kuat dicapai oleh penjual gula di agen (80,00\%). Agen menggunakan bahan kemasan sangat kuat karena berat gula yang dibeli dalam jumlah besar melebihi $10 \mathrm{~kg}$ dalam sekali beli.

Pada aspek desain kemasan, predikat menarik hanya dicapai pada produk gula yang dibeli di minimarket (66,67\%). Sedangkan pada toko $(60,00 \%)$ dan agen gula $(60,00 \%)$ berkonotasi negatif. Konsumen lebih suka membeli gula di toko karena berat gula yang dikemas sangat bervariasi $(30,00 \%)$. Sedangkan konsumen yang mempunyai daya beli tinggi baik untuk kebutuhan maupun untuk dijual kembali lebih senang membeli di agen (40,00\%) ) dengan harapan harga yang lebih murah ketika membeli dalam jumlah yang besar. Meskipun berat produk gula yang dijual di minimarket tidak bervariasi $(66,67 \%)$, pembelian gula tetap ramai karena terdapat daya tarik gengsi, desain kemasan menarik, dan bermerek. Hal ini merupakan sebuah trend tersendiri bagi segmen konsumen kelas ekonomi menengah ke atas.

Penjual produk gula baik dari toko, minimarket, dan agen di kebupaten Jember (letak PG Semboro) pada dasarnya mempunyai kesamaan preferensi konsumen terhadap produk gula pasir yang dijual. Tetapi terdapat perbedaan pada berat gula yang dibeli dalam sekali pembelian di toko. Toko tradisional di kabupaten Jember mempunyai selera 
konsumen yang suka membeli gula dengan berat $1 \mathrm{~kg}(13,33 \%)$ (lebih berat daripada di kabupaten Lumajang). Hal ini dikarenakan untuk melakukan penghematan konsumen akibat rantai distribusi yang sedikit lebih panjang sehingga jika toko di kabupaten Jember ingin melakukan variasi berat gula yang dijual akan berdampak menjual dengan harga yang sedikit lebih mahal daripada di kabupaten Lumajang.

Karakteristik Produk Gula Pasir Ditinjau Elemen Produk, Harga, Promosi, dan

\section{Distribusi dalam Konsep Business to Business}

\section{Produk}

Persepsi konsumen terhadap kualitas dapat diperkuat dengan merek yang sudah kokoh dibenak mereka. Kekuatan merek dapat membantu konsumen dalam mempersepsikan kualitas suatu produk. Preferensi konsumen terhadap merek produk gula memiliki keberagaman dalam tiap retail. Untuk toko lebih menyukai tradisional (L:33,33\%; J:40,00\%), minimarket lebih suka modern (L:53,33\%; J:53,33\%), dan agen (L:60,00\%; J:80,00\%) menggunakan merek klasik. Keseragaman preferensi terletak pada penggunaan bahasa pada merek yang dominan menyukai bahasa Indonesia (toko: L:56,67\%; J:60,00\%; minimarket: L:40,00\%; J:46,67\%; agen: L:80,00\%; J:60,00\%).

Dalam segi penggunaan kata kunci "gula" toko (L:40,00\%; J:40,00\%) dan minimarket (L:53,33\%; J:46,67\%) menyukai penggunaan kata "gula" pada merek sedangkan pada agen (L:100,00\%; J:100,00\%) tidak demikian. Rekomendasi yang diberikan berdasarkan penelitian ini adalah penggunaan nama merek pada produk gula hendaknya memprioritaskan penggunaan bahasa Indonesia. Meskipun menurut Hernawan (2012) konsumen merek pembeli adalah individu dalam $B 2 B$ masingmasing anggota memiliki sikap yang berbeda terhadap merek apapun. Tetapi dengan didasarkan pada keseragaman minat preferensi konsumen maka bentuk perbedaan tersebut dapat ditempatkan pada suatu wadah.

Preferensi konsumen terhadap kualitas produk gula memiliki keberagaman dalam tiap retail. Untuk toko lebih menyukai besar kasar $(43,33 \%)$ dan lembut $(50,00 \%)$, minimarket besar kasar (L:53,33\%; J:46,67\%), dan agen menggunakan gula lembut (L:60,00\%; J:60,00\%). Keseragaman preferensi terletak pada warna Kristal gula yang dominan menyukai putih bening (toko: L:43,33\%; J:46,67\%; minimarket: L:60,00\%; J:73,33\%; agen: L:80,00\%; J:60,00\%)serta aroma gula yang netral (tidak berbau) (toko: L:70,00\%; J:63,33\%; minimarket: L:80,00\%; J:80,00\%; agen: L:100,00\%; J:100,00\%). Rekomendasi yang diberikan berdasarkan penelitian ini adalah penggunaan kualitas pada produk gula hendaknya memprioritaskan penggunaan warna kristal putih bening dan netral (tidak berbau).

Karena menurut Umar (2003) ketika menentukan dimensi kualitas barang hendaknya memperhatikan conformance (kesesuaian) berkaitan dengan tingkat 
kesesuaian terhadap spesifikasi yang telah ditetapkan sebelumnya berdasarkan keinginan pelanggan. Konfirmasi mereflesikan derajat ketetapan antara karakteristik desain produk dan karakteristik standar yang telah ditetapkan. Selain itu juga perlu fit and finish (respons) sifat subjektif berkaitan dengan perasaan pelanggan mengenai keberadaaan produk yang berkualitas. Preferensi konsumen terhadap kemasan produk gula memiliki keberagaman dalam tiap retail. Ditinjau dari bahan kemasan untuk toko lebih menyukai plastik $(36,67 \%)$ dan kertas tebal $(30,00 \%)$, minimarket plastik dan kaleng (46,67\%), dan agen menggunakan karung (L:100\%; J:100,00\%). Ditinjau dari bentuk kemasan untuk toko (L:43,33\%; J:50,00\%) dan minimarket (L:40,00\%; J:40,00\%) lebih menyukai bentuk silinder, dan agen (L:100,00\%; J:100,00\%) lebih suka bentuk kaleng dan sak. Ditinjau dari desain kemasan untuk toko lebih menyukai warna mencolok ( $L: 50,00 \%$; J:50,00\%), minimarket menyukai modern (L:46,67\%; J:60,00\%), dan agen lebih suka warna klasik (L:100,00\%; J:100,00\%).

\section{Harga}

Strategi penetapan harga produk baru, yaitu prinsip strategi penetapan harga untuk produk baru adalah agar produk baru mampu memberikan kontribusi nyata bagi pertumbuhan pasar dengan dukungan penetapan harga yang tepat. Preferensi konsumen terhadap ukuran produk gula memiliki keberagaman dalam tiap retail. Ditinjau dari aspek cara pembagian berat gula yang pelanggan sukai toko lebih memilih dikemas dalam karung yang lebih kecil (43,33\%) dan jadi satu kemasan tanpa pembagian $(46,67 \%)$, minimarket memilih terbagi menjadi beberapa sachet $(46,67 \%)$ dan dikemas dalam karung yang lebih kecil (46,67\%), serta untuk agen lebih memilih jadi satu kemasan tanpa pembagian (L:100,00\%; J:100,00\%).

Ditinjau dari ukuran berat gula yang sering pelanggan sukai konsumen di retail toko lebih menyukai ukuran $1 \mathrm{~kg}$ (L:46,67\%; J:40,00\%), minimarket 1/2 kg dan $1 \mathrm{~kg}$ (L:40,00\%; J:40,00\%), dan agen lebih dari $10 \mathrm{~kg}$ (L:100,00\%; J: 100,00\%). gula pada ukuran tertentu agar tepat sesuai sasaran yang diinginkan konsumen. Preferensi konsumen terhadap pengaturan harga produk gula memiliki keseragaman dalam tiap retail. Ditinjau dari aspek bonus dan diskon yang pelanggan sukai, konsumen gula di toko (L:43,33\%; J:36,67\%), minimarket (L:33,33\%; J:40,00\%), dan agen (L:100,00\%; J:100,00\%) menyukai diskon dan bonus diberikan pada transaksi pada jumlah yang banyak. Ditinjau dari aspek perubahan harga yang pelanggan kehendaki, konsumen gula di toko (L:40,00\%; J:36,67\%), minimarket (L:26,67\%; J:33,33\%), dan agen (L:60,00\%; J:80,00\%) menyukai harga berubah menyesuaikan ukuran per kemasan.

Hasil penelitian ini hendaknya memberikan pertimbangan khusus pada PG Djatiroto dan PG Semboro untuk memprioritaskan pengaturan harga gula dengan sistem diskon dan bonus diberikan pada transaksi pada jumlah yang banyak serta harga berubah menyesuaikan ukuran per kemasan. Rekomendasi ini didasarkan dari data 
penelitian dan pendapat menurut Triton (2008) yang menyatakan bahwa dalam market penetration pricing, penetapan harga yang rendah untuk produk baru dengan tujuan untuk menarik sejumlah besar pembeli dan memperoleh pangsa pasar yang besar. Serta discount and allowance pricing, pengurangan harga sebagai bentuk penghargaan terhadap pelanggan yang memberikan respons seperti membayar lebih awal atau mempromosikan produk.

\section{Promosi}

Preferensi konsumen terhadap promosi offline produk gula memiliki keberagaman dalam tiap retail. Ditinjau dari aspek promosi tradisional yang disukai pelanggan toko menyukai reklame ( $\mathrm{L}: 50,00 \%$; J:46,67\%), minimarket menyukai brosur (L:40,00\%; J:33,33\%), dan katalog produk, serta agen menyukai spanduk dan Koran (L:80,00\%; J:100,00\%). Ditinjau dari aspek promosi media massa, toko menyukai radio (L:46,67\%; J:40,00\%), minimarket lebih menyukai radio dan televisi (L:40,00\%; J:46,67\%), serta agen memilih koran sebagai media promosi (L:60,00\%; J:80,00\%).

Preferensi konsumen terhadap promosi online produk gula memiliki keseragaman dalam tiap retail. Ditinjau dari aspek promosi gula dalam sosial media yang mudah ditemukan pelanggan toko (L:43,33\%; J:33,33\%), minimarket (L:53,33\%; J:46,67\%), dan agen (L:80,00\%; J:100,00\%) memilih facebook sebagai media sosial yang efektif. Ditinjau dari aspek promosi gula dalam bentuk web yang mudah ditemukan pelanggan toko (L:33,33\%; J:40,00\%) lebih memilih website resmi PTPN XI, minimarket (L:40,00\%; J:40,00\%) lebih memilih website resmi PTPN XI dan website toko online, serta agen (L:80,00\%; J:100,00\%) menyukai website toko online dalam melakukan promosi.

\section{Distribusi}

Preferensi konsumen terhadap promosi distribusi produk gula memiliki keberagaman dalam tiap retail. Ditinjau dari aspek retail tradisional yang disukai pelanggan toko menyukai toko atau warung (L:43,33\%; J:40,00\%), minimarket juga menyukai toko atau warung (L:53,33\%; J:60,00\%), dan agen (L:80,00\%; J:60,00\%) lebih memilih tempatnya sendiri. Ditinjau dari aspek retail modern yang disukai pelanggan terdapat keseragaman, toko (L:33,33\%; J:43,33\%), minimarket (L:40,00\%; J:66,67\%), dan agen (L:80,00\%; J:60,00\%) lebih memilih distribusi di minimarket. Hasil penelitian ini hendaknya memberikan pertimbangan khusus pada PTPN XI Djatiroto dan Semboro untuk memprioritaskan pengaturan distribusi modern yang terpusat di minimarket.

Distribusi gula yang disukai konsumen pada toko tradisional (L:43,33\%; J:40,00\%) adalah dari PTPN XI ke agen kemudian menuju ke toko. Distribusi gula yang disukai konsumen pada minimarket (L:40,00\%; J:66,67\%) adalah dari PTPN XI langsung menuju ke minimarket. Distribusi gula yang disukai konsumen pada agen (L:80,00\%; J:60,00\%) adalah dari PTPN XI langsung menuju ke agen. 


\section{Karakteristik Produk Gula Pasir Baru yang Diinginkan Konsumen}

Perilaku konsumen adalah tindakan yang langsung terlibat untuk mendapatkan, mengkonsumsi, dan menghabiskan produk dan jasa, termasuk proses keputusan yang mendahului dan mengikuti tindakan ini. Perilaku konsumen dipengaruhi dan dibentuk oleh pengaruh lingkungan (budaya, kelas sosial, pengaruh pribadi, keluarga, dan situasi), perbedaan individu (sumber daya konsumen, motivasi dan keterlibatan, pengetahuan, sikap, kepribadian, gaya hidup dan demografi), dan proses psikologis (pengolahan informasi, pembelajaran, dan perubahan sikap dan perilaku).

Tabel 4

Karakteristik Umum Gula Baru yang Diinginkan Konsumen

\begin{tabular}{lll}
\hline Bauran & Penjabaran Dimensi & Karakteristik yang Diperoleh \\
\hline Produk & $\begin{array}{l}\text { Bahasa yang diinginkan pelanggan } \\
\text { pada produk gula }\end{array}$ & Indonesia \\
\cline { 2 - 3 } & $\begin{array}{l}\text { Warna kristal yang menjadi pilihan } \\
\text { Pelanggan }\end{array}$ & Putih bening \\
& Aroma gula yang pelanggan sukai & Tidak berbau (netral) \\
\hline Harga & $\begin{array}{l}\text { Bonus dan diskon yang pelanggan } \\
\text { Sukai }\end{array}$ & $\begin{array}{l}\text { Diskon dan bonus diberikan pada } \\
\text { transaksi pada jumlah yang banyak }\end{array}$ \\
\cline { 2 - 3 } & $\begin{array}{l}\text { Perubahan harga yang pelanggan } \\
\text { Kehendaki }\end{array}$ & $\begin{array}{l}\text { Harga berubah menyesuaikan } \\
\text { ukuran per kemasan }\end{array}$ \\
\hline Promosi & Promosi gula dalam sosial media & Facebook \\
\hline yang mudah ditemukan pelanggan & \\
\hline Distribusi & Retail modern yang disukai & Karakteristik yang Diperoleh \\
\hline & $\begin{array}{l}\text { pelanggan untuk membeli produk } \\
\text { Gula }\end{array}$ & Minimarket \\
\hline & Disribusi langsung dari PTPN XI & Toko tradisional \\
\hline
\end{tabular}

Dengan demikian, faktor yang ada dalam bauran pemasaran (marketing mix) merupakan variabel-variabel yang diharapkan mampu menciptakan kepuasan konsumen, atau dengan kata lain variabel-variabel tersebut akan mempengaruhi kepuasan konsumen dalam membeli suatu produk. Kepuasan pelanggan akan berimbas kepada loyalitas pelanggan, sehingga usaha yang dibangun akan terus bertahan dan berkembang (Rachmawati, 2011).

\section{CONCLUSION}

Preferensi konsumen terhadap bauran produk, harga, promosi, dan distribusi pada toko, minimarket, dan agen yaitu:

1. Bauran produk sangat penting menurut konsumen gula pasir di toko, minimarket, dan agen, bauran produk yang disukai konsumen adalah: (a) Produk gula yang disukai konsumen pada toko tradisional adalah gula tidak bermerek, butiran besar kasar, warna 
putih bening, sangat bersih, dan beraroma netral. Kemasan yang disukai dengan bahan plastik berbentuk balok dengan warna mencolok; (b) Produk gula yang disukai konsumen pada minimarket adalah gula bermerek dengan desain modern berbahasa Indonesia serta menggunakan kata "gula", butiran besar kasar, warna putih bening, sangat bersih, dan beraroma netral. Kemasan yang disukai dengan bahan plastik berbentuk silinder dengan warna modern; (c) Produk gula yang disukai konsumen pada agen adalah gula tidak bermerek, butiran lembut, warna putih bening, sangat bersih, dan beraroma netral. Kemasan yang disukai dengan bahan karung berbentuk kaleng (sak goni) dengan warna klasik.

2. Bauran harga sangat penting menurut konsumen gula pasir di toko dan agen, bauran harga yang disukai konsumen adalah: (a) Harga gula yang disukai konsumen pada toko tradisional adalah diatur jadi satu kemasan tanpa pembagian dengan berat $1 \mathrm{~kg}$, diskon dan bonus pada pembelian jumlah yang banyak, serta harga berubah menyesuaikan ukuran per kemasan; (b) Harga gula yang disukai konsumen pada minimarket adalah diatur terbagi menjadi beberapa sachet dengan berat $1 / 2 \mathrm{~kg}$ dan $1 \mathrm{~kg}$, diskon dan bonus pada pembelian jumlah yang banyak, serta harga berubah menyesuaikan ukuran per kemasan; (c) Harga gula yang disukai konsumen pada agen adalah diatur jadi satu kemasan tanpa pembagian dengan berat lebih dari $10 \mathrm{~kg}$, diskon dan bonus pembelian jumlah yang banyak, serta harga berubah menyesuaikan ukuran per kemasan.

3. Bauran promosi sangat penting menurut konsumen gula pasir di toko dan agen, bauran promosi yang disukai konsumen adalah: (a) Promosi gula yang mudah dijangkau konsumen pada toko tradisional adalah reklame, radio, facebook, dan website resmi PTPN XI; (b) Promosi gula yang mudah dijangkau konsumen pada minimarket adalah brosur, radio, katalog, televisi, facebook, dan website resmi PTPN XI; (c) Promosi gula yang mudah dijangkau konsumen pada agen adalah spanduk, koran, dan website toko online.

4. Bauran distribusi sangat penting menurut konsumen gula pasir di toko dan agen, bauran distribusi yang disukai konsumen adalah: (a) Distribusi gula yang disukai pada toko tradisional adalah dari PTPN XI ke agen kemudian menuju ke toko; (b) Distribusi gula yang disukai pada minimarket adalah dari PTPN XI langsung menuju ke minimarket; (c) Distribusi gula yang disukai pada agen adalah dari PTPN XI langsung menuju ke agen.

Hendaknya dapat menjadi informasi penting dan stimulus pada PTPN XI Djatiroto dan Semboro yang bergantung pada regulasi Tujuh Samurai, agar dapat menjual produk gula baru secara langsung ke konsumen sehingga keuntungan yang dihasilkan lebih tinggi. Direkomendasikan sistem wholesale distribution of industrial products, toko grosir berfungsi sebagai perantara antara pabrik dan konsumen akhir. Hendaknya menjadi bahan pertimbangan bagi perusahaan PTPN XI yaitu PG Djatiroto dan PG Semboro untuk memproduksi gula pasir yang baik sesuai dengan preferensi dan keinginan konsumen. 
Direkomendasikan pada PG Djatiroto dan PG Semboro untuk memproduksi gula baru yang didistribusikan secara mandiri melalui $B 2 B$ pada toko, minimarket, dan agen dengan mempertimbangkan bauran produk, harga, promosi dan distribusi. Hendaknya dapat menstimulus perusahaan PG Djatiroto dan PG Semboro untuk berinvestasi baik on-farm dan off-farm guna menunjang kualitas produk sesuai dengan yang syaratkan oleh pemerintah melalui SNI produk makanan. Hendaknya dijadikan sebagai bahan pertimbangan dalam strategi pemasaran dan segmen pasar yang paling sesuai dengan hasil produksi 16 Pabrik Gula yang dimiliki oleh perusahaan PTPN XI (Persero).

\section{REFERENCES}

BPS Jember. 2012. Kabupaten Jember Tahun 2012. http://jemberkab.bps.go.id/ index.php?hal=tabel\&id=4. 12 Juli 2014.

BPS Lumajang. 2012. Kabupaten Lumajang Tahun 2012. http://lumajangkab.bps. go.id/index.php?hal=tabel\&id=4. 12 Juli 2014.

Ebert, Ronald J and Griffin, Ricky W. 2000. Business Essentials: International Edition. Third Edtion. Upper Saddle River New Jersey: Prentice Hall, Inc.

Fayshal, Abung dan Henny Medyawati. 2013. Analisis Strategi Pemasaran Produk Asuransi Jiwa Pada Bumi Putera Syariah Cabang Depok. Jurnal Asuransi dan Manajemen Resiko. Vol. 1, No. 02, Septemberv 2013.

Goodwin, Dennis W. 1994. Life and Health Insurance Marketing. LOMA. Hafid. 2010. Profil Lengkap PTPN XI. http://ptpnxihafid.blogspot.com/2010/12/ profillengkapptpn-xi.html. 19 September 2014.

Harian Sumut Pos. 2009. Tujuh Samurai Kuasai Gula. http://www.hariansumutpos.com/arsip/?p=9110. 12 Juli 2014.

Hendrayani, Imas Nunik. 2008. Analisis Tingkat Kepuasan dan Loyalitas Konsumen Terhadap Produk Gula Pasir Merek Gulaku di Kota Bogor. Program Studi Manajemen Agribisnis. Fakultas Pertanian. IPB. Bogor.

Hernawan. 2012. Efektifnya Pemasaran Business to Business. http://www.marketing.co.id/efektifnya-pemasaran-business-to-business/. Tanggal 5 Agustus 2014.

Kotler, P. 1997. Manajemen Pemasaran: Analisis, Perencanaan, Implementasi, dan Kontrol. Jakarta: Prenhalindo.

Pemkab Lumajang. 2014. Kecamatan Jatiroto. http://www.lumajang.go.id/kecjtr.php. Tanggal 12 Mei 2014.

Proboyekti, Umi. 2008. Pengantar Penelitian. Bahan Ajar Mata kuliah Bahasa Indonesia. Fakultas Teknologi Informasi. Program Studi Sistem Informasi.

PTPN XI. 2009. PG Semboro. http://www.ptpn-11.com/pg-semboro.html. 19 September 2014.

Rachmawati, Rina. 2011. Peranan Bauran Pemasaran (Marketing Mix) Terhadap Peningkatan Penjualan (Sebuah Kajian terhadap Bisnis Restoran). Jurnal Kompetensi Teknik Vol. 2, No. 2, Mei 2011. 
Rahayu, Santi. 2011. Dongkrak Penggilingan, PTPN XI Revitalisasi PG Jatiroto dan Semboro. http://news.detik.com/surabaya/read/2011/05/13 /153731/1639163/ 1066/dongkrak-penggilingan-ptpn-xi-revitalisasi-pg-jatiroto-dan-semboro. 19

September 2014. Roberts, John et al. 2005. Kotler on Strategic Marketing. Journal of Urban 6.20 .10

RWJF. 2008. Stratified Purposeful Sampling. http://www.qualres.org/HomeStra3813.html. 2 Agustus 2014.

Sandro. 2013. Gula PG Semboro, Produk Unggulan Dari Jember. http://www.ptpn11.com/gula-pg-semboro-produk-unggulan-dari-jember.html. 19 September 2014.

Singarimbun, Masri dan Sofian Effendi. 1995. Metode Penelitian Survei. Jakarta : LP3ES.

Sugiyono. 2009. Metode Penelitian Kuantitatif, Kualitatif, dan R and D. Alfabeta: Bandung.

Suhasnan, N. 2012. Analisis Efisiensi Penggunaan Faktor-Faktor Produksi pada Produksi Gula (Studi Pada Petani Tebu PT PG Rajawali II Unit PG Sindanglaut Kab. Cirebon). Universitas Pendidikan Indonesia. Jakarta.

Surabaya Pagi. 2013. SBY dan Pakde juga Penasaran Lihat Pabrik Gula Jatiroto. http://www.surabayapagi.com/index.php?read=SBY-dan-Pakde-juga-PenasaranLihat-Pabrik-Gula-Jatiroto. Tanggal 12 Mei 2014.

Taylor, Michael dan Yayat Supriatna. 2013. Penelisikan tentang „Samurai Gula Pasir' di Indonesia. https://id.berita.yahoo.com/penelisikan-tentang-samurai-gula-pasir-diindonesia-051531139.html. Tanggal 24 Juli 2014.

Teddlie, Charles and Fen Yu. 2007. Mixed Methods Sampling: A Typology With Examples. Journal of Mixed Methods Research. Volume 1 Number 1. January 2007 77-100.

Triton PB. 2008. Marketing Strategi Meningkatkan Pangsa Pasar dan Daya Saing. Yogyakarta: Tugu Publisher.

Umar, H. 2003. Riset Pemasaran dan Perilaku Konsumen. Jakarta: Gramedia Pustaka Utama.

VOA. 2014. Samurai Gula Permainkan Harga di Pasar Indonesia. http://www.voaindonesia.com/content/samurai-gula-kontrol-harga-dipasarindonesia/ 1627861.html. Tanggal 24 Juli 2014. 